\title{
Dynamic Model to Predict Effect of Race Waviness on Vibrations Associated with Deep-Groove Ball Bearing
}

\author{
Pyung Hwang $^{1 \dagger}$ and Van Trang Nguyen ${ }^{2}$ \\ ${ }^{1}$ School of Mechanical Engineering, Yeungnam University 214-1 Dae-Dong, \\ Gyeongsan, Gyeongbuk 712-749, Korea \\ ${ }^{2}$ Dept. of Mechanical Engineering, Yeungnam University 214-1 Dae-Dong, \\ Gyeongsan, Gyeongbuk 712-749, Korea
}

(Received November 4, 2013 ; Revised December 20, 2013 ; Accepted December 27, 2013)

\begin{abstract}
This paper presents a numerical model for investigating the structural dynamics response of a rigid rotor supported on deep-groove ball bearings. The numerical model was used to investigate the influence of race waviness on the dynamic characteristics of a rotor ball bearing system, which is very important from a design viewpoint. The forth-order Runge-Kutta numerical integration technique was applied to determine the time displacement response, Poincarè map, and frequency spectra. The analysis demonstrated that the model can be used as a tool for predicting the nonlinear dynamic behavior of a rotor ball bearing system under different operating conditions. The results of this study may help further understanding of the nonlinear dynamics of a rotor bearing system.
\end{abstract}

Keywords - dynamic response, ball bearing, ball passage frequency, rotor bearing system

\section{Introduction}

Ball bearings are very important in numerous rotating machinery systems. The prediction and analysis of the dynamic behavior of rotor systems are important because their rotating components possess amounts of energy that can be transformed into vibrations. These vibrations not only affect the performance of rotor system, but may also cause serious damage to the rotating machinery systems. Hence this field has become more challenging since nonlinear analysis is far more difficult compared to the analysis of the linear phenomena. Nonlinearities in rotor systems can be caused by many reasons [1] such as Hertzian contact force, internal radial clearance, surface waviness [2], and stiffness coefficient. Waviness is defined as the geometric imperfection of inner or outer race in ball bearing, and it is also considered one of the sources of vibration [3].

\footnotetext{
${ }^{\dagger}$ Corresponding author : phwang@yu.ac.kr

(O) Submited paper is presented in 2013 fall conference of KSTLE (2013. 10. 16. 18/yeosu)
}

The aim of this study is to develop a numerical model for investigating the dynamic properties of rotor system supported by ball bearings under the effect of bearing running waviness. In the analytical formulation, the waviness of rolling elements is modeled by sinusoidal function. The Hertzian contact theory is applied to calculate the elastic deflection and non-linear contact force. A two-degree of freedom system is considered with the assumption that there is no friction between the rolling elements and raceways of ball bearings. The rolling elements are positioned symmetrically such that their motion is synchronized. The $4^{\text {th }}$ order Runge-Kutta numerical integration technique has been applied to solve the nonlinear differential equations. The results are presented in form of time displacement response, Poincarè map, and frequency spectra. The analysis demonstrates that the surface waviness is an important parameter affecting on the dynamic characteristics of rotor bearing system $[4,5]$. The model can also be used as a tool for predicting nonlinear dynamic behavior of rotor system under different operating conditions. 


\section{The Problem Formulation}

Since a real rotor bearing system is very complicated and difficult to model [6-10], the analysis of the dynamic behavior of the system is done based on the following assumptions while developing the mathematical model as follows:

1. Torsional vibration of rotor and gyroscopic effects may be neglected and only transverse vibration of rotor should be considered.

2. The outer race of the ball bearing is fixed to a rigid support. The inner race is fixed rigidly to the shaft. There is no slipping of balls.

3. Constant vertical radial force acts on the bearing.

4. Elastic deformation between race and ball gives a nonlinear force deformation relation, which is obtained by using Hertzian theory.

Zeillinger and K Köttritsch [11] noted that additional damping usually occurs between the bearing outer race and its housing. It is known that ball bearing have very low inherent damping. This damping would be effective only for small vibration amplitude [12]. Krämer [13] has provided as estimation of the bearing damping and [14] also the bearing coefficient of ball bearing is well within the range of $33.75 \mathrm{Ns} / \mathrm{m}$ to $337.5 \mathrm{Ns} / \mathrm{m}$. A value of $c=200 \mathrm{Ns} / \mathrm{m}$ was chosen.

\section{2-1. Waviness model}

$$
A_{j}=A_{i}+A_{o} \sin \left(\frac{2 \pi L}{\lambda}\right)
$$

Waviness is defined as the geometric imperfection of inner or outer race in a ball bearing, and it is considered one of the sources of vibration. These are global sinusoidal shaped imperfections on the outer race surface of the bearing components as in Fig. 1. Waves can be described in terms of two parameters: wavelength $(\lambda)$, and its amplitude (A). The amplitude of wave at the contact angle can be expressed as follows: where $A_{i}$ is initial wave amplitude and $A_{0}$ is maximum amplitude of wave in radial direction of outer race; $L$ is the arc length of wave of inner race,

$$
L=r \times \theta_{j}
$$
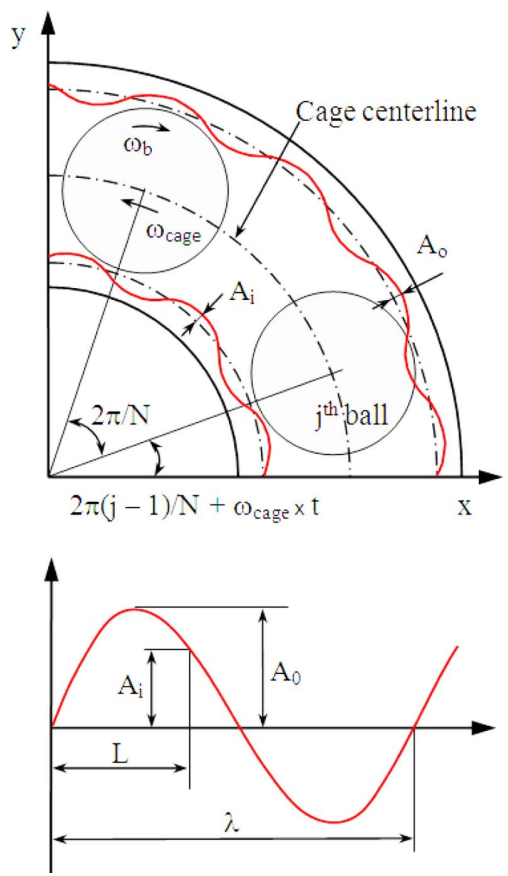

Fig. 1. Race waviness model.

$$
\lambda=\frac{2 \pi r}{N_{w}}
$$

Finally, $A_{j}=A_{i}+A_{o} \sin \left(N_{w} \theta_{j}\right)$

where $N_{w}$ is number of wave lobes and $\theta_{j}$ is the position of $\mathrm{j}^{\text {th }}$ ball; $r$ is inner race radius.

Because the inner race is moving at the speed of the shaft and the ball center at the speed of the cage so the contact angle $\left(\theta_{j}\right)$ is given by

$$
\theta_{j}=\frac{2 \pi}{N}(j-1)+\omega \times t, \quad j=1, \ldots, N
$$

\section{2-2. Nonlinear ball bearing force}

As shown in Fig. 2, the tangent velocity of the contact point between the ball and the inner race $V_{A}$, outer race $V_{B}$, respectively, can be given by

$$
\begin{aligned}
& V_{A}=0 \\
& V_{B}=\omega_{B} \cdot R_{B}
\end{aligned}
$$

Since the outer race is assumed to be stationary, $V_{A}=$ 0 . Therefore, the tangent velocity of the cage is

$$
V_{\text {cage }}=\frac{1}{2}\left(V_{A}+V_{B}\right)=\frac{V_{B}}{2}=\frac{\omega_{B} \times R_{B}}{2}
$$




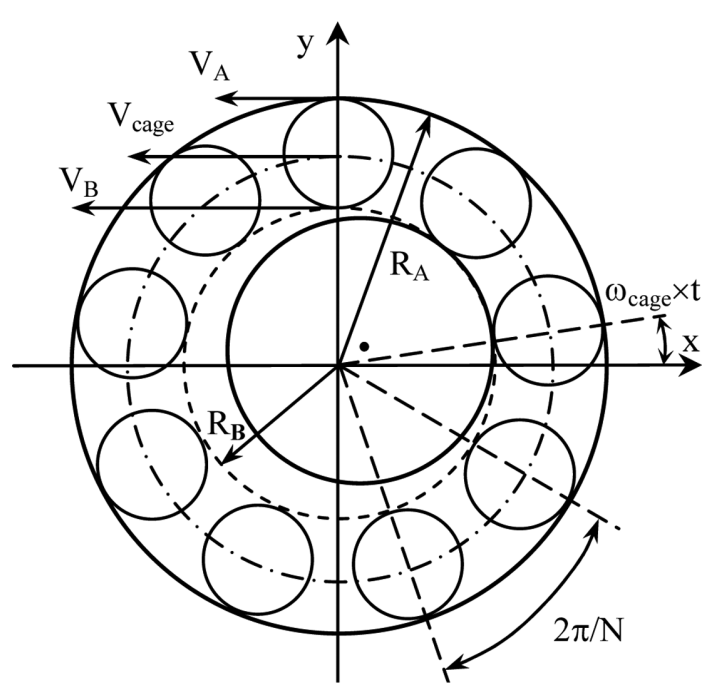

Fig. 2. Schematic diagram of ball bearing.

$$
\omega_{\text {cage }}=\frac{V_{\text {cage }}}{\left(R_{A}+R_{B}\right) / 2}=\omega_{\text {rotor }} \times \frac{R_{B}}{R_{A}+R_{B}}
$$

The inner race is fixed to the shaft, $\omega_{B}=\omega_{\text {rotor }}$ Then, the angular velocity of the cage is written by

$$
\begin{aligned}
& \omega_{v c}=\omega_{\text {cage }} \times N=\omega_{\text {rotor }} \times\left(\frac{R_{B}}{R_{A}+R_{B}} \times N\right)
\end{aligned}
$$

The varying compliance frequency or the ball passage frequency can be expressed in terms of the cage speed times the number of balls, $N$.

According to the Hertzian contact theory [Hertz, 1896], the local Hertzian contact force $F_{j}$ between the $\mathrm{j}^{\text {th }}$ ball and the race is given as follows [15]:

$$
F_{j}=K \times \delta_{j}^{1.5}
$$

The contact stiffness coefficient $K$, can be given by the stiffness coefficient between the ball and each race [16], $k_{i}$ and $k_{0}$ in series as follows:

$$
K=\frac{1}{\left[\left(\frac{1}{k_{i}}\right)^{\frac{2}{3}}+\left(\frac{1}{k_{0}}\right)^{\frac{2}{3}}\right]^{\frac{3}{2}}}
$$

where $k_{i}$ and $k_{0}$ can be determined by elastic modulus and Poisson's ratio and curvature sum of the contact points as
Table 1. Geometrical properties of the system

\begin{tabular}{lc}
\hline \hline Radial clearance $(\gamma)$ & $0.01 \mu \mathrm{m}$ \\
\hline Radial load $(\mathrm{W})$ & $6 \mathrm{~N}$ \\
\hline Mass of rotor $(\mathrm{m})$ & $1.2 \mathrm{~kg}$ \\
\hline Damping factor $(\mathrm{c})$ & $200 \mathrm{Ns} / \mathrm{m}$ \\
\hline Force due to unbalance rotor $\left(\mathrm{F}_{\mathrm{u}}\right)$ & $0.9 \mathrm{~N}$ \\
\hline Number of the ball, $(\mathrm{N})$ & 10 \\
\hline Number of wave lobes, $\left(\mathrm{N}_{\mathrm{w}}\right)$ & 8 \\
\hline Inner race radius, $\left(\mathrm{R}_{\mathrm{B}}\right)$ & $9.37 \mathrm{~mm}$ \\
\hline Outer race radius, $\left(\mathrm{R}_{\mathrm{A}}\right)$ & $14.13 \mathrm{~mm}$ \\
\hline Ball diameter, $(\mathrm{D})$ & 4.76 \\
\hline Poisson's ratio & 0.3 \\
\hline Elastic modulus, $(\mathrm{E})$ & $2.0 \times 10^{11}\left(\mathrm{~N} / \mathrm{m}^{2}\right)$ \\
\hline Time step $(\Delta \mathrm{t})$ & $10^{-5} \mathrm{~s}$ \\
\hline
\end{tabular}

from Harris [15]. The geometrical properties of the system is in Table $1, K=7.055 \times 10^{9}\left(\mathrm{~N} / \mathrm{mm}^{1.5}\right)$.

Based on the Hertzian contact force between inner and outer race and the ball, the total restoring force is the sum of restoring force from each of the rolling elements. The "+" sign subscript in the equation (13, 14) signify this step change in the restoring force expression and models the clearance non-linearity. If the expression inside the bracket is greater than zero, then the ball at the angular location $\theta_{j}$ is within the angular contact zone and it is loaded giving rise to a restoring force. If the expression within the brackets is negative or zero, then the ball is not in the load zone, and restoring force is set to zero. So the contact force between the $\mathrm{j}^{\text {th }}$ ball and inner race can be expressed as,

$$
\begin{aligned}
& F_{x}=\sum_{j=1}^{N} K\left[\left(x \cos \theta_{j}+y \sin \theta_{j}\right)-\gamma\right]_{+}^{1.5} \cos \theta_{j} \\
& F_{y}=\sum_{j=1}^{N} K\left[\left(x \cos \theta_{j}+y \sin \theta_{j}\right)-\gamma\right]_{+}^{1.5} \sin \theta_{j}
\end{aligned}
$$

The mathematical model takes into account the sources of nonlinearities in rotor bearing system. After assembling the inertia, ball bearing force, damping force, race waviness and constant vertical force acting on the inner race, the dynamic equations 
of the system are established as follows:

$$
\begin{aligned}
& m \ddot{x}+c \dot{x}=\sum_{j=1}^{N} K\left[\left(x \cos \theta_{j}+y \sin \theta_{j}\right)-\left(\gamma+A_{j}\right)\right]_{+}^{1.5} \cos \theta_{j}= \\
& =W+F_{u} \cos \left(\omega_{\text {rotor }} \times t\right) \\
& m \ddot{y}+c \dot{y}=\sum_{j=1}^{N} K\left[\left(x \cos \theta_{j}+y \sin \theta_{j}\right)-\left(\gamma+A_{j}\right)\right]_{+}^{1.5} \sin \theta_{j}= \\
& =F_{u} \sin \left(\omega_{\text {rotor }} \times t\right)
\end{aligned}
$$

\section{Results and Discussion}

The nonlinear governing equations of motion (15) are solved by the $4^{\text {th }}$ order Runge-Kutta numerical integration technique to obtain and radial displacement of the rolling element and the shaft. The initial conditions are set to $x_{0}=10^{-6}(\mathrm{~m}), y_{0}=10^{-6}(\mathrm{~m}), x^{\prime}{ }_{0}=0$ and $y_{0}^{\prime}=$ $0 ; K=7.05 \times 10^{9}\left(\mathrm{~N} / \mathrm{m}^{1.5}\right)$. In order to observe the effect of race waviness, time displacement response, Poincarè map, and frequency domain vibrations of shaft rotor bearing system are obtained to determine the dynamic behavior of system [4].

The amplitude of race waviness is one of the key factors affecting on the dynamic characteristics of a rotor system. Fig. 3(a, b, c) show the response at a speed of $6,000 \mathrm{rpm}$ without waviness in inner and outer race. For horizontal displacement response, the natural frequency coincides with the varying compliance (a)

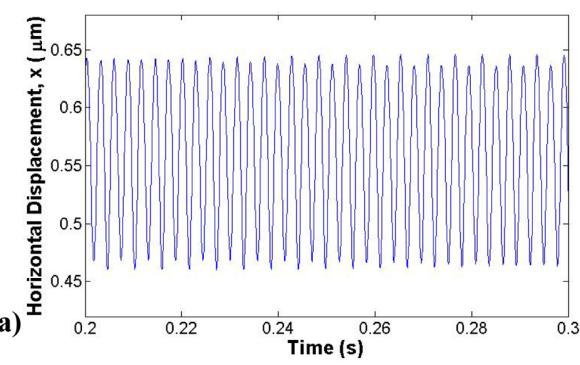

(b)

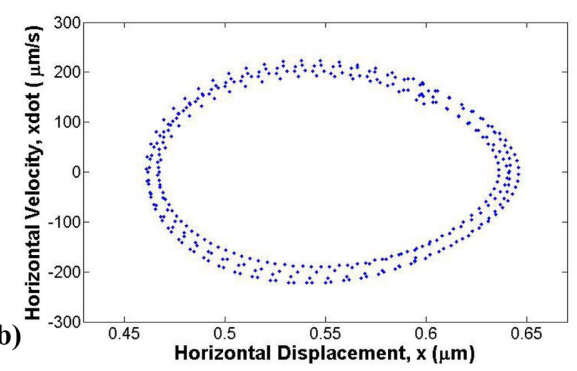

(c)

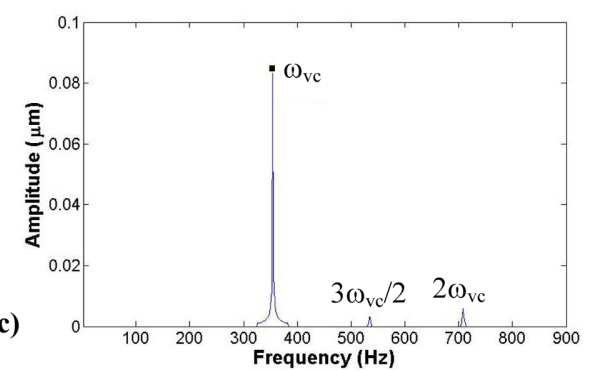

(d)

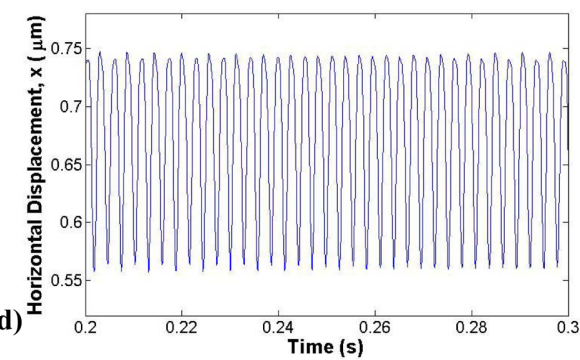

(e)

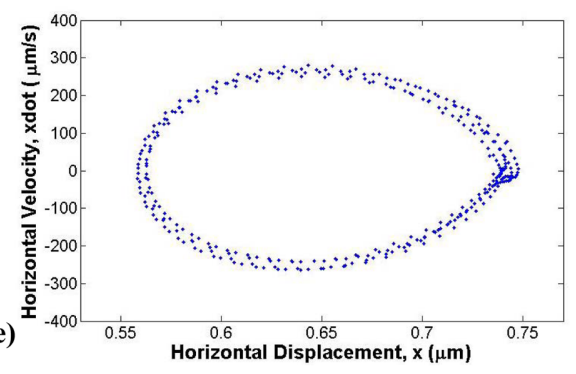

(f)

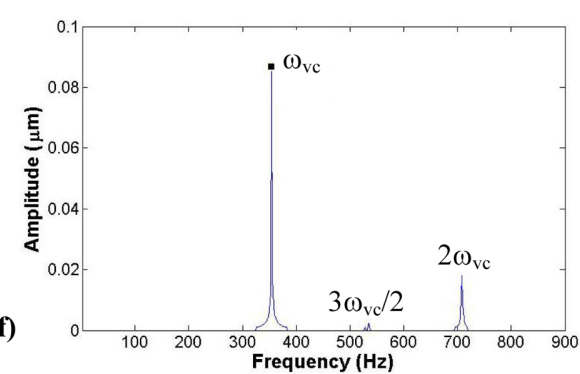

Fig. 3. a), b), c) Displacement response with time, Poincarè map for displacement response, and FFT for horizontal displacement response at 6,000 rpm, respectively; when $\mathbf{A}_{\mathrm{i}}=\mathbf{0}, \mathbf{A}_{0}=0$. sd), e), f) Displacement response with time, Poincarè map for displacement response, and FFT for horizontal displacement response at 6,000 rpm, respectively; when $A_{i}=0.1, A_{0}=0$. 
frequency $\left(\omega_{v c}=354 \mathrm{~Hz}\right)$. The peak amplitude is 0.0846 $\mu \mathrm{m}$ on the horizontal direction. The major peaks amplitude of vibration appear at $3 \omega_{v c} 2=531 \mathrm{~Hz}, 2 \omega_{v c}$ $=708 \mathrm{~Hz}$. The amplitude of peaks are $0.003 \mu \mathrm{m}$ and $0.0058 \mu \mathrm{m}$ at $3 \omega_{v c} 2=531 \mathrm{~Hz}$ and $2 \omega_{v c}=708 \mathrm{~Hz}$, respectively. For horizontal displacement response without outer race waviness and with amplitude of inner race waviness, $A_{i}=0.1 \mu \mathrm{m}$ as in Fig. $3(\mathrm{~d}, \mathrm{e}, \mathrm{f})$. The peak amplitude of vibration is $0.0867 \mu \mathrm{m}$ at $\omega_{v c}=$ $354 \mathrm{~Hz}$. The major peaks are at $3 \omega_{\mathrm{vc}} / 2=531 \mathrm{~Hz}$, and $2 \omega_{v c}=708 \mathrm{~Hz}$. The Poincarè maps showed in Fig. 3(b) and 3(e), give an indication of a quasi-periodic response because of "net" structure.

Fig. 4(a, b, c) show the response with amplitude of inner race waviness, $A_{i}=0.1 \mu \mathrm{m}$ and amplitude of race waviness, $A_{0}=0.3$ at $6,000 \mathrm{rpm}$. The natural frequency coincides with the varying compliance frequency $\left(\omega_{v c}=354 \mathrm{~Hz}\right)$. The peak amplitude is 0.1018 $\mu \mathrm{m}$ on horizontal direction. The major peaks amplitude of vibration appear at $\omega_{v c} / 4=90 \mathrm{~Hz}, 5 \omega_{v c} / 2=890$ Hz. Fig. 4(d, e, f) show the response with amplitude of inner race waviness, $A_{i}=0.1 \mu \mathrm{m}$ and amplitude of race waviness, $A_{0}=0.5$ at $6,000 \mathrm{rpm}$. The natural frequency coincides with the varying compliance frequency $\left(\omega_{\mathrm{vc}}\right.$ $=354 \mathrm{~Hz}$ ). The peak amplitude is $0.111 \mu \mathrm{m}$ on horizontal direction. The major peaks amplitude of vibration appear at $3 \omega_{v c} / 2=531 \mathrm{~Hz}, 2 \omega_{v c}=708 \mathrm{~Hz}$, and $5 \omega_{v d} / 2=890 \mathrm{~Hz}$. With the orbits of a dense structure in (a)

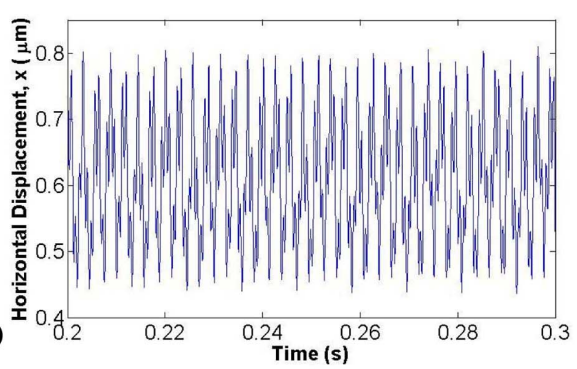

(b)

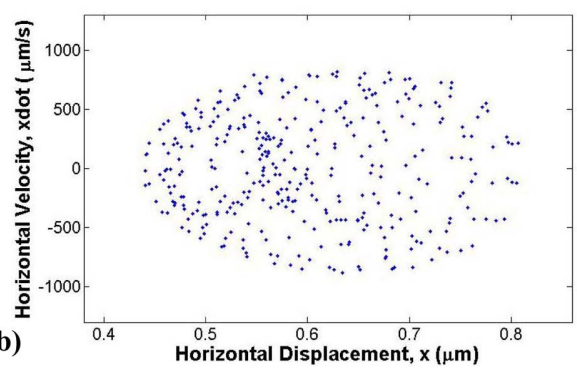

(c)

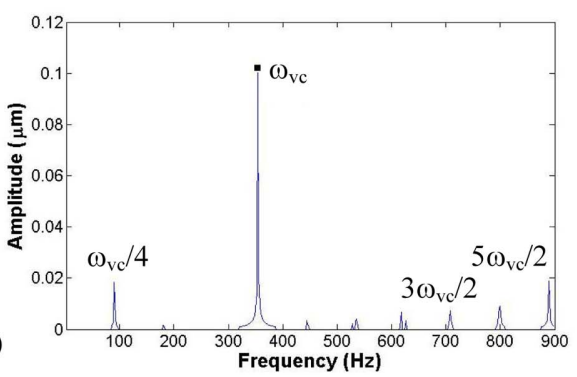

(d)
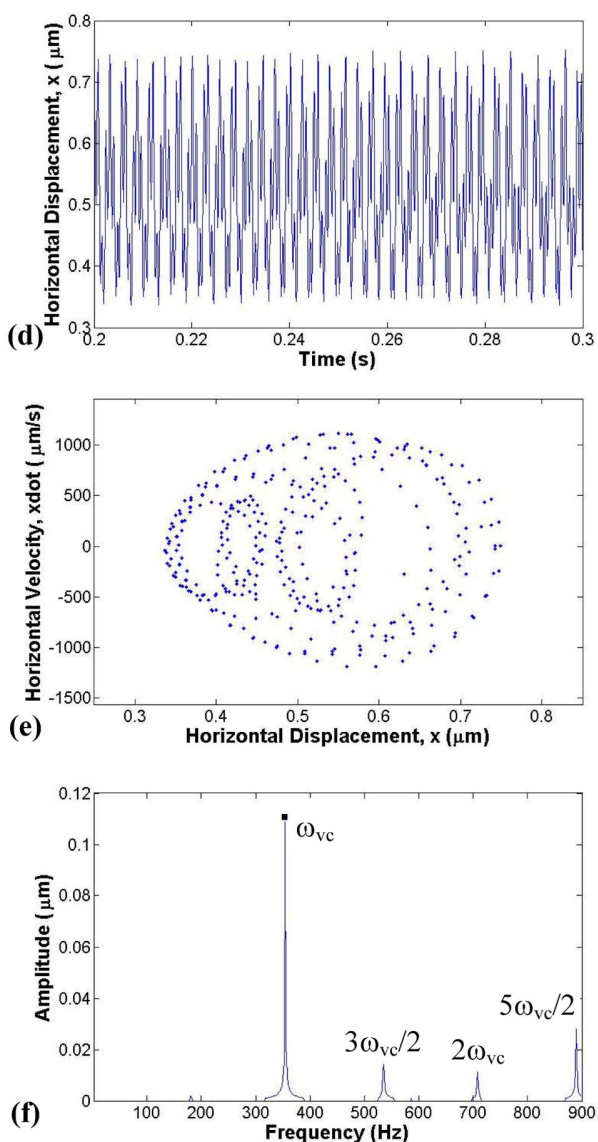

Fig. 4. a), b), c) Displacement response with time, Poincarè map for displacement response, and FFT for horizontal displacement response at $6,000 \mathrm{rpm}$, respectively; when $\mathrm{A}_{\mathrm{i}}=0.1, \mathrm{~A}_{0}=0.3$. d), e), f) Displacement response with time, Poincarè map for displacement response, and FFT for horizontal displacement response at $6,000 \mathrm{rpm}$, respectively; when $A_{i}=0.1, A_{0}=0.5$. 
the Poincarè maps, which give indication of chaotic response, as shown in Fig. 4(b) and 4(e).

It is seen from the solutions of the effect of race waviness by certain conditions, the amplitude response are modulation. Without waviness, the peak amplitudes of vibrations at the varying compliance frequency are insignificant. When increasing amplitude of outer race waviness, the peak amplitudes of vibrations at the varying compliance frequency are more significant. This is also demonstrated by Poincarè maps.

\section{Conclusions}

In this paper, a two-degree of freedom nonlinear model of a rotor-ball bearing system has been developed to obtain the nonlinear vibration response by varying amplitude of race waviness. Nonlinear analysis of this model was performed numerically using $4^{\text {th }}$ order Runge-Kutta integration method.

The results show that the dynamic characteristics behavior of the system is sensitive to small variation of the system parameters. The race waviness of ball bearing is an important parameter for vibration analysis of rotor bearing system and should be considered at the design stages of rotating machinery systems. The model can be used as a tool for predicting nonlinear dynamic behavior of rotor ball bearing system under different operating conditions. Moreover, the study may contribute to a further understanding of the nonlinear dynamics of rotor bearing system.

\section{Nomenclature}

$m \quad$ : Mass of rotor, $\mathrm{kg}$

$c \quad$ : Equivalent viscous damping factor, $\mathrm{Ns} / \mathrm{m}$

$F_{x} / F_{y}$ : Hertzian contact force on horizontal/vertical direction, $N$

$L \quad$ : Arc length of wave of surface waviness, $\mu \mathrm{m}$

$F_{u} \quad$ : Force due to unbalance rotor, $N$

$K$ : Hertzian contact stiffness, $N / \mathrm{m}^{3 / 2}$

$N / N_{w}$ : Number of balls / wave lobes
$R_{B} \quad:$ Inner race radius, $m m$

$R_{A} \quad$ : Outer race radius, $m m$

$r \quad$ : Inner race radius, $m m$

$t \quad$ : Time, $s$

$A_{i} \quad$ : Initial wave amplitude, $\mu m$

$A_{0} \quad$ : Maximum wave amplitude, $\mu m$

$V_{\text {cage }}:$ Translational velocity of cage center, $\mathrm{mm} / \mathrm{s}$

$V_{a} \quad$ : Translational velocity of the inner race, $\mathrm{mm} / \mathrm{s}$

$V_{b} \quad$ : Translational velocity of the outer race, $\mathrm{mm} / \mathrm{s}$

$W \quad$ : Radial load, $N$

$\gamma \quad$ : Internal radial clearance, $\mu m$

$\lambda$ : Wavelength of surface waviness, $\mu m$

$\omega_{\text {rotor }}:$ Angular speed of rotor, $\mathrm{rad} / \mathrm{s}$

$\omega_{\text {cage }}:$ Angular speed of the cage, $\mathrm{rad} / \mathrm{s}$

$\omega_{A} \quad$ : Angular speed of the inner race, $\mathrm{rad} / \mathrm{s}$

$\omega_{B} / \omega_{b}$ : Angular speed of the outer race / ball, $\mathrm{rad} / \mathrm{s}$

$\theta_{j} \quad$ : Angular location of $\mathrm{j}_{\mathrm{th}}$ rolling element, $\mathrm{rad} / \mathrm{s}$

\section{Acknowledgments}

This research was supported by Yeungnam University Research Fund Program.

\section{References}

[1] Ehrich, F., "Observations of nonlinear phenomena in rotordynamics," Journal of system design and dynamics, Vol. 2, No. 3, pp. 641-651, 2008.

[2] Cheng, Mei, Meng, Guang, and Wu, Bingyu, "Nonlinear dynamics of a rotor-ball bearing system with Alford force," Journal of Vibration and Control, Vol. 18, No. 1, pp. 17-27, 2011.

[3] Wardle, F. P. and Poon, S. Y., "Rolling bearing noise, cause and curve," Chartered Mechanical Engineering, pp. 36-40, 1983.

[4] Hwang, Pyung, Pan, Galina and Khan, Polina "Natural Frequency Analysis of Sliders and Head/Disk Interaction Detection by Acoustic Emission," J. Korean Soc. Tribol. Lubr. Eng. (International), Vol. 5, No. 1, 28-31, June 2004.

[5] Hwang, Pyung, Nguyen, Van Trang, "Dynamic Analysis of Effect of Number of Balls on Rotor-Bearing System," J. Korean Soc. Tribol. Lubr. Eng., Vol. 29, No. 4, pp. 248-254, August 2013.

[6] Fukata, S., Gad, E. H., Kondou, T. A., and Tamura, H., "On the radial vibrations of ball bearings (computer simulation)," Bulletin of the. JSME 28, pp. 899-904, 
1985.

[7] El-Saeidy, F. M. A., "Finite element modeling of rotorshaft-rolling bearing system with consideration of bearing nonlinearities," Journal of Vibration and Control 4, pp. 514-602, 1998.

[8] Tiwari, M., Gupta, K., and Prakash, O., "Experimental study of a rotor supported by deep groove ball bearing," International Journal of Rotating Machinery, Vol. 8, No. 4, pp. 243-258, 2002.

[9] Tiwari, M., Gupta, K., and Prakash, O., "Effect of radial internal clearance of a ball bearing on the dynamics of a balanced horizontal rotor," Journal of Sound and Vibration, Vol. 238, No. 5, pp. 723-756 2000.

[10] Waardle, F. P., "Vibration forces produced by waviness of the rolling surfaces of thrust loaded ball bearings. Part I: Theory," Proceeding of the IMechE Vol. 202, No. C5, pp. 305-12, 1988.

[11] Zeillinger, R. and Köttritsch, H., "Damping in a roll- ing bearing arrangement," Evolution, 1/96, 1996.

[12] Lewis, P. and Malanoski, S. B. "Rotor-Bearing Dynamics Design Technology, Part IV: Ball Bearing Design Data," AFAPL-TR-65-45, 1965.

[13] Krämer, E., "Dynamics of Rotor and Foundations", Springer-Verlag, New York (1993).

[14] Gupta, T. C., Gupta, K., and Sehgal, D. K., "Nonlinear Dynamics and Chaos of an Unbalanced Flexible Rotor Supported by Deep Groove Ball Bearings with Radial Internal Clearance," IUTAM Symposium on Emerging Trends in Rotor Dynamics, 2011.

[15] Harris, T. A., "Rolling Bearing Analysis," $4^{\text {th }}$ Edition, John Wiley \& Sons, Inc., New York, 2001.

[16] Jang, G. H. and Jeong, S. W. "Nonlinear Excitation Model of Ball Bearing Waviness in a Rigid Rotor Supported by Two or More Ball Bearings Considering Five Degrees of Freedom," Transactions of the ASME, Vol. 124, 2002. 